\title{
Backcross Introgression of the Cucumis hystrix Genome Increases Genetic Diversity in U.S. Processing Cucumber
}

\author{
Isabelle Y. Delannay ${ }^{1,4}$, Jack E. Staub ${ }^{1,2}$, and Jin Feng Chen ${ }^{3}$ \\ Vegetable Crops Unit, U.S. Department of Agriculture, Agricultural Research Service, Department of \\ Horticulture, University of Wisconsin, 1575 Linden Drive, Madison, WI 53706
}

\begin{abstract}
AdDITIONAL INDEX wORDs. Cucumis sativus, combining ability, marker assisted selection, morphological traits, multivariate analysis

ABstract. The genetic base of commercial cucumber (Cucumis sativus L.) is extremely narrow (about $3 \%-8 \%$ polymorphism). Wide-based crosses within $C$. sativus [i.e., $C$. sativus var. sativus $\times$ C. sativus var. hardwickii (R.) Alef.] and interspecific hybridization attempts before 1995 have not substantially increased genetic diversity for plant improvement. However, in 1995, an amphidiploid (Cucumis hytivus Chen and Kirkbride) was derived from a $C$. sativus $\times$ Cucumis hystrix Chakr. mating. A derivative of this amphidiploid was used herein to broaden the genetic base of cucumber through backcross introgression $[(C$. sativus $\times C$. hytivus $) \times C$. sativus]. Initially, the combining ability of eight genetically diverse lines was investigated for days to anthesis (DA), sex expression (SEX), lateral branch number (LBN), fruit per plant (FP), fruit length:diameter ratio (L:D), and salt-processing ability [i.e., processed fruit color (exterior and interior), shape, and seed cavity characteristics]. Based on the combining ability, inbred backcross lines [IBL $\left(\mathrm{BC}_{2} \mathrm{~S}_{3}\right)$ ] were developed from an original gynoecious determinate line WI 7023A [C. sativus (recurrent parent)] $\times$ monoecious indeterminate line WI 7012A $(C$. sativus $\times C$. hytivus derived) mating, where 30 of $392(8 \%)$ $\mathrm{BC}_{1}$ progeny were selected based on their diversity at 16 mapped marker loci. These progeny were used to develop $\mathrm{BC}_{2}$ progeny, which were then self-pollinated without further selection to produce $94 \mathrm{IBL}$. These IBL were genotyped and evaluated in the open field in two plantings in 2008 for DA, SEX, LBN, leaf size, FP, and L:D. The genetic distance (GD) between parental lines was 0.85 , and the GD among IBL ranged between 0.16 and 0.75 . Multivariate analyses indicated that IBL differed from parental lines and possessed considerable morphological and genotypic diversity that could be used to broaden the genetic base of commercial U.S. processing cucumber.
\end{abstract}

The genetic diversity of cucumber [C. sativus $(2 \mathrm{n}=2 \mathrm{x}=24)]$ market types and exotic germplasm (i.e., PIs) has been well documented and found to be extremely narrow $[3 \%-8 \%$ polymorphisms among elite and exotic germplasm and $12 \%$ between botanical varieties C. sativus var. sativus and C. sativus var. hardwickii (Dijkhuizen et al., 1996; Horejsi and Staub, 1999; Meglic and Staub, 1996; Meglic et al., 1996; Miliki et al., 2003; Staub et al., 1997, 1999)]. This lack of genetic diversity has been an impediment to the genetic improvement of cucumber in several commercially important market classes (Staub et al., 2008).

Harlan and de Wet (1971) introduced the concept of gene pools (primary, secondary, and tertiary) to explain genetic diversity relationships within species. Primary gene pools consist of individuals that hybridize freely, produce viable offspring, and exhibit chromosome pairing and crossing-over in hybrid progeny (Harlan et al., 1973). In the case of C. sativus, the $\approx 1386$ C. sativus var. sativus accessions and crosscompatible feral relatives (e.g., C. sativus var. hardwickii)

Received for publication 19 Feb. 2010. Accepted for publication 26 May 2010. ${ }^{1}$ Current address: Vegetable Crops Unit, U.S. Department of Agriculture, Agricultural Research Service, Department of Horticulture, University of Wisconsin, 1575 Linden Drive, Madison, WI 53706.

${ }^{2}$ Current address: U.S. Department of Agriculture, Agricultural Research Service, Forage and Range Research Laboratory, 696 North 1100 E., Logan, UT 84322.

${ }^{3}$ Current address: State Key Laboratory of Crop Genetics and Germplasm Enhancement, Key Laboratory of Southern Vegetable Crop Genetic Improvement, Nanjing Agricultural University, Nanjing, 210095 China.

${ }^{4}$ Corresponding author. E-mail: Idelannay@yahoo.com. resident in the U.S. National Plant Germplasm System (U.S. Department of Agriculture, 2010) are representative of its primary gene pool. The secondary gene pool of $C$. sativus includes cross-incompatible (e.g., wild African species) or sparingly cross-compatible (e.g., C. hystrix) species (Chen et al., 1997; Chung et al., 2006). The tertiary gene pool of cucumber consists of distantly related species from other genera or subgenera (e.g., Cucumis melo L. and Cucurbita L. spp.) that do not hybridize with cucumber (Chung et al., 2006; Staub et al., 1987, 1992c). Historically, attempts to exploit resources beyond the primary cucumber gene pool (e.g., C. melo, Cucumis metuliferus E. Mey ex Schrad.) have been unsuccessful or not repeatable (Staub et al., 1987, 1992c).

In 1995, Chen et al. successfully made an interspecific cross between $C$. sativus var. sativus [C (primary gene pool)] and C. hystrix $[\mathrm{H}(2 \mathrm{n}=2 \mathrm{x}=24$, secondary gene pool) (Chen et al., $1997)$. Because the $F_{1}$ progeny $(2 n=2 x=19)$ derived from this mating were both male and female sterile, chromosome doubling was performed to produce a fertile amphidiploid (HHCC, $2 \mathrm{n}=4 \mathrm{x}=38$ ) via somaclonal variation during in vitro embryo culture (Chen et al., 1998). This amphidiploid was subsequently self-pollinated for several generations, resulting in fertile germplasm that was designated a new species, C. hytivus $(2 \mathrm{n}=4 \mathrm{x}=38)$ (Chen and Kirkbride, 2000).

The incorporation of genes from the secondary gene pool of cucumber such as $C$. hystrix is potentially important for plant improvement in this species. For instance, novel genes, such as those for disease resistance to gummy stem blight [causal agent Didymella bryoniae (Fuckel) Rehm.], can be found in 
C. hystrix, but are not present in cultivated cucumber (Chen et al., 2003). However, traits that negatively impact $C$. sativus yield or quality can also be introduced during introgression of the $C$. hystrix genome.

The inbred backcross breeding method (Wehrhahn and Allard, 1965) has shown potential for improving population diversity and yield among cucumbers (Owens et al., 1985). Backcrossing with concurrent initial molecular-based genotyping and selection for genetic diversity in $C$. sativus $\times C$. hystrixderived populations may be avenues for increasing genetic diversity in cucumber (Fan et al., 2006). Therefore, a project was designed to: 1) develop a genetically diverse array of C. hytivus-derived IBL in a U.S. processing cucumber genetic background and examine their morphological diversity, and 2) determine the stability of these IBL with regard to yield and quality component traits. The creation and genetic assessment of $C$. hytivus-derived IBL provides information and germplasm for the direct incorporation of novel genes into elite commercial cucumber germplasm.

\section{Materials and Methods}

In Summer 2005, a North Carolina Design II combining ability evaluation of potential parental lines for IBL development was conducted in a field nursery [Plainfield loamy sand (Typic Udipasamment) soil] at the University of Wisconsin Experimental Station in Hancock, WI (UWESH) (Delannay, 2009). Based on the combining ability, lines WI 7023A and WI 7012A were chosen for crossing to develop IBL.

The determinate, gynoecious line WI 7023A $\left(\mathrm{BC}_{4} \mathrm{~S}_{3}\right)$ was created through selection and backcrossing [Gy-7 (recurrent parent, University of Wisconsin) and H19 (donor parent; University of Arkansas, Fayetteville)] to identify a smallstatured genotype for once-over mechanical harvest operations. It originated from the same populations that were used to develop recombinant inbred lines for the mapping of quantitative trait loci in U.S. processing cucumber (Staub et al., 2002). The late flowering, indeterminate, monoecious line WI 7012A is a $\mathrm{BC}_{1} \mathrm{~S}_{3}$ line derived from a $C$. hytivus $\times C$. sativus [longfruited Chinese $C$. sativus cv. Beijingjietou (recurrent backcross parent)] mating (Chen et al., 2003). The relatively high yielding, multiple lateral branching line WI 7012A produces warty, light-green fruit of commercially unacceptable shape and quality (Fig. 1).

Combining ability. During Summer 2006 and Summer 2007, a new combining ability of the C. hytivus-derived line WI 7012A was evaluated in a North Carolina Design II at UWESH to further evaluate its potential trait contributions for the U.S. processing cucumber market (i.e., compared with WI $1983 \mathrm{G}$-derived hybrid progeny). USDA lines 7012A (C. hytivus derived) and $1983 \mathrm{G}$ (C. sativus) were crossed to C. sativus paternal U.S. processing breeding lines Gy-7, H19, WI 7023A, WI 7011H, and WI 6996A to produce $\mathrm{F}_{1}$ progeny (Table 1). Lines WI 7023A, WI 7011H, and WI 6996A were obtained from the USDA cucumber project at Madison, WI, and lines Gy-7 (synonym G421) and H19 were obtained originally from the University of Wisconsin (Madison) and the University of Arkansas (Fayetteville), respectively. The field design for each year was a random complete block design (RCBD) with four blocks, where each block had end borders and consisted of 20 plants in single rows spaced $15 \mathrm{~cm}$ apart on

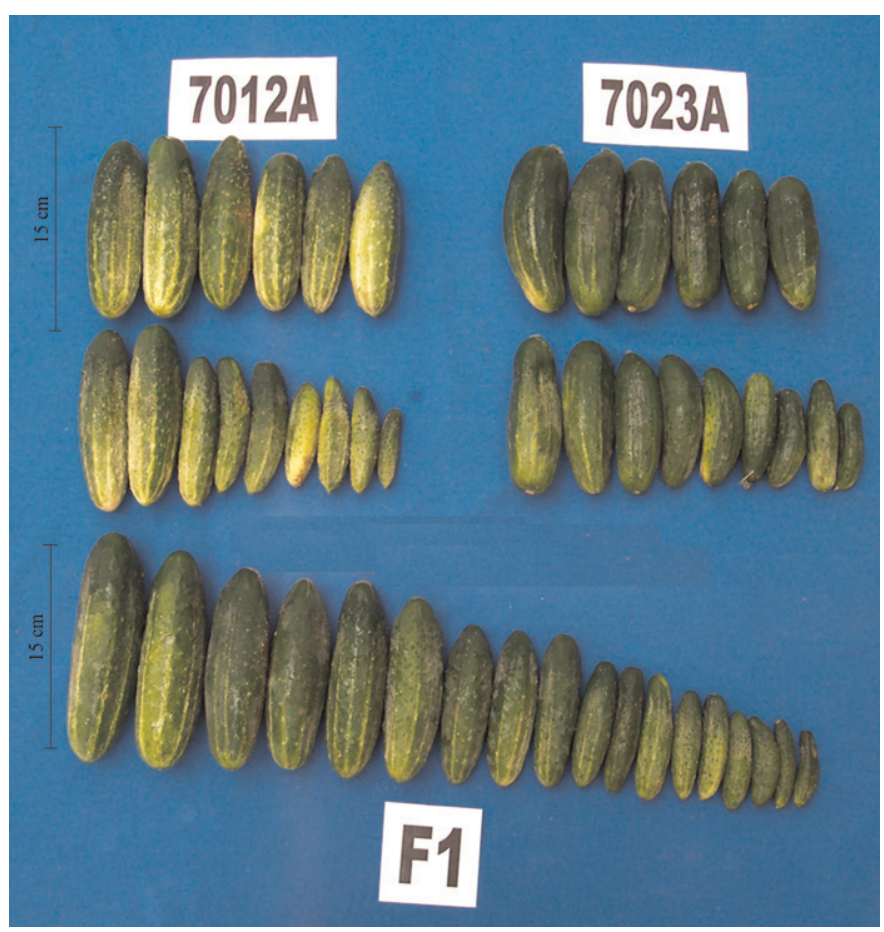

Fig. 1. Fruit of Cucumis hystrix-derived WI 7012A and Cucumis sativus line WI $7023 \mathrm{~A}$ and their $\mathrm{F}_{1}$ progeny.

Table 1. Characteristics of U.S. processing cucumber lines employed to develop cross-progeny using a North Carolina Design II mating scheme.

\begin{tabular}{lccc}
\hline Lines & Plant growth habit $^{\mathrm{z}}$ & Leaf size $^{\mathrm{y}}$ & Sex expression $^{\mathrm{x}}$ \\
\hline WI 7012A & De & $L L$ & $\mathrm{M}$ \\
WI 7023A & $d e$ & $L L$ & $\mathrm{G}$ \\
WI 1983G & $d e$ & $L L$ & $\mathrm{G}$ \\
Gy-7 & $d e$ & $L L$ & $\mathrm{G}$ \\
H19 & $D e$ & $l l$ & $\mathrm{M}$ \\
WI 7011H & $D e$ & $L L$ & $\mathrm{G}$ \\
WI 6996A & $D e$ & $L L$ & $\mathrm{G}$
\end{tabular}

$\overline{{ }^{2} \text { Indeterminate and determinate growth habits conditioned by } D e \text { and }}$ de, respectively.

' Leaves of standard leaf size conditioned by $L L$ and little leaf size conditioned by $l l$ measure 80 to $100 \mathrm{~cm}^{2}$ and 30 to $40 \mathrm{~cm}^{2}$, respectively. xPlants are gynoecious $(\mathrm{G})$ if all flowers are pistillate and monoecious [M (pistillate and staminate) $]$ if fewer than $50 \%$ of flowers are staminate.

1.5-m centers (about 44,400 plants/ha). Seeds of the hybrids and the parental lines were sown in mid-June of each year.

Plants were evaluated for days to anthesis (DA), sex expression (SEX), lateral branch number (LBN), fruit per plant (FP), and length:diameter ratio (L:D) on all plants within a plot. DA, SEX, and LBN data were collected on a per plant basis, whereas FP and L:D data were taken of a per plot basis. The DA was recorded as the number of days between sowing and the appearance of the first fully expanded corolla. Individual plants within plots were given a numerical value based on their relative gynoecy as gynoecious (2), predominantly female (1), or monoecious (0) for SEX. A plant was considered gynoecious if all flowers within the first 10 nodes of the plant 
were pistillate. Plants were classified as predominately female if greater than $51 \%$ of flowers on the first 10 nodes were pistillate. If plants possessed $50 \%$ or fewer pistillate flowers within the first 10 nodes, they were designated monoecious. LBN was recorded when individual plants reached anthesis. Only lateral branches longer than $5 \mathrm{~cm}$ on the first 10 nodes were recorded.

Fruit per plant, and fruit length and width were recorded on a per-plot basis at each of seven harvests at 1-week intervals. Harvest began when a majority of the fruit was greater than $2 \mathrm{~cm}$ in diameter (equivalent to USDA 2A grade). Mean fruit L:D was obtained per plot by measuring the length and diameter of five to 10 randomly selected fruit ranging between 2.5 and $3.0 \mathrm{~cm}$ in diameter (equivalent to USDA 2A-3A grade). FP was calculated by dividing the total number of fruit per plot at each harvest by the number of plants.

Data from each year were initially combined for analysis of variance (ANOVA) to define year, blocks, and germplasm (parents and progeny) effects, and genotype-by-environment interactions using SAS (version 9.1 for Windows; SAS Institute, Cary NC). Year and year-by-line interactions were treated as random effects; blocks and germplasm were treated as fixed effects. Least square means for each trait were calculated using PROC GLM in conjunction with LSMEANS option.

General combining ability (GCA) and specific combining ability (SCA) were calculated according to Hallauer and Miranda employing the trait means of each hybrid $\left(F_{1}\right)$ (Hallauer and Miranda, 1988).

Development of IBL. An $\mathrm{F}_{1}$ progeny derived from a WI 7023A (female parent) by WI 7012A (male parent) mating was backcrossed to WI $7023 \mathrm{~A}$ to produce the $\mathrm{BC}_{1}$ generation. Tissue from young expanding leaves of $392 \mathrm{BC}_{1}$ seedlings at the first leaf stage was collected and DNA was extracted according to Fazio et al. (2003).

Thirty $\mathrm{BC}_{1}$ individuals were selected (selection intensity equals about $8 \%$ ) for pollination based on variation (i.e., heterozygosity) at 16 mapped SSR (4), SCAR (5), SNAP (6), and bacterial artificial chromosome (BAC)-end (1) marker loci (Table 2; Fazio et al., 2002, 2003; Nam et al., 2005). These selected $\mathrm{BC}_{1}$ individuals were pollinated by WI 7023A to produce $\mathrm{BC}_{2}$ progeny.

Because of trait variability observed in the $\mathrm{BC}_{1}$ generation (Delannay, 2009) and the marker-based heterogeneity of $\mathrm{BC}_{1}$ plants, marker-assisted selection (MAS) was not practiced on $\mathrm{BC}_{2}$ progeny. About eight seeds per $\mathrm{BC}_{2}$ line were randomly selected for self-pollination to produce the $\mathrm{BC}_{2} \mathrm{~S}_{1}$ generation followed by single seed descent to generate 94 IBL (Tanksley et al., 1996; Wehrhahn and Allard, 1965).

Phenotypic evaluation of IBL. The parental lines (WI 7023A and WI 7012A), $F_{1}$ and $F_{2}$ progeny, and 94 IBL were sown in a RCBD in two open-field plantings at UWESH on 3 June and 1 July 2008. Each planting consisted of three blocks, each containing 10 plants set $15 \mathrm{~cm}$ apart on $1.5 \mathrm{~m}$ row centers (about 44,400 plants/ha).

Data on DA, SEX, LBN, and leaf size, where standard leaf size $(L L)$ is 80 to $100 \mathrm{~cm}^{2}$ and little leaf size $(l l)$ measures 30 to $40 \mathrm{~cm}^{2}$ (Staub et al., 1992b), were recorded on a per plant basis as previously described. FP and L:D data were obtained on a per plot basis over three harvests as described above.

Data from each planting were initially combined for ANOVA to define planting, block, and line (parents and IBL) effects using the PROC GLM procedure in SAS. All variables were treated as random effects. Least square means were calculated for each line in each planting (two) using the LSMEANS option in the PROC GLM procedure. These means were then used to calculate rank correlations $\left(r_{s}\right)$ between plantings for each trait using the PROC CORR statement with the SPEARMAN option.

Repeatability measures were performed for all variables to predict expected trait performances for the IBL examined (Falconer and Mackay, 1989). Estimates of variance for planting, block, and lines were obtained using the COVTEST option in the PROC MIXED procedure of SAS, where planting, block, and lines were treated as random variables for repeatability estimations. Repeatability (r) was calculated according to Falconer and Mackay (1989) with their SE estimated according to Hallauer and Miranda (1988).

Multivariate analyses were performed using phenotypic data to further describe parental (WI 7023A and WI 7012A) and IBL relationships by employing principal component analysis (PCA) using the PROC PRINCOMP procedure of SAS. The average SEX, LBN, percentage of little-leaf genotypes $(l l), \mathrm{FP}$, and fruit L:D were calculated by line and used as variables in PCA. Principal components (PC 1-3) were initially visualized using the three-dimensional plot option within NTsys (Rohlf, 1998).

Molecular evaluation of IBL. Each IBL in the first planting was sampled for DNA extraction and analysis at UWESH by harvesting the smallest expanding leaf from each of 10 plants per plot in the first two blocks. The leaves within each IBL were bulked and held at about $4{ }^{\circ} \mathrm{C}$ (about $5 \mathrm{~h}$ ) until transfer to $-80{ }^{\circ} \mathrm{C}$ storage, after which DNA was extracted according to Fazio et al. (2003) to provide samples of 94 IBL for molecular genotyping. Polymerase chain reaction (PCR) was performed using these and samples of the original two parental lines (WI 7023A and WI 7012A) as template DNA primed with 37 codominant markers (Table 2) (Fazio et al., 2003; Kong et al., 2006; Nam et al., 2005; Ritschel et al., 2004). Band polymorphisms identified by markers that detected differences between 5 and 30 bp were visualized using 3\% agarose gels run at $250 \mathrm{~V}$ for 4 to $6 \mathrm{~h}$, and amplicon differences greater than $30 \mathrm{bp}$ were detected using $1.6 \%$ agarose gels run at $250 \mathrm{~V}$ for $2 \mathrm{~h}$. For codominant markers that detected $<5 \mathrm{bp}$ differences, Alexa-labeled 2'-deoxyuridine 5' -triphosphates (dUTPs) were added to the PCR master mix, and then polymorphisms were identified using fragment analysis performed at the University of Wisconsin Biotechnology Center in Madison. Subsequently, band-size differences were analyzed using GeneMarker (version 1.2; Softgenetics, State College, PA).

Marker PCR products were evaluated for predicted segregation of codominant and dominant markers ratios $(1: 2: 1$ and $3: 1$, respectively) by chi-square analyses using the Yate's correction factor (Pearson, 1900; Yates, 1934).

Multidimensional scaling analysis (MDS) was performed using 37 codominant markers that defined the parents and IBL using NTsys to determine genetic relationships between IBL (Table 2). Rogers (1972) GD as modified by Wright (1978) was used in the Simgend procedure of NTsys to construct a GD matrix for the 94 IBL, the two parents, and a $C$. hystrix accession. Genetic relationships between IBL were visualized using the three-dimensional plot option of NTsys. 
Table 2. Polymorphic markers and their expected fits to genotypic ratios in $\mathrm{BC}_{2} \mathrm{~S}_{3}$ U.S. processing cucumber progeny derived from markerselected $\mathrm{BC}_{1}$ progeny and their allelic frequencies.

\begin{tabular}{|c|c|c|c|c|c|c|c|}
\hline Marker & $\begin{array}{c}\text { Marker } \\
\text { type }^{z}\end{array}$ & $\begin{array}{l}\text { Linkage } \\
\text { group }^{\mathrm{y}}\end{array}$ & $\begin{array}{l}\text { Selection } \\
\text { at } \mathrm{BC}_{1}{ }^{\mathrm{x}}\end{array}$ & $\begin{array}{c}\text { Evaluation } \\
\text { of IBL }\end{array}$ & $\begin{array}{c}\text { Expected allele } \\
\text { frequency }^{\mathrm{v}}\end{array}$ & $\begin{array}{c}\text { Observed allele } \\
\text { frequency }^{\mathrm{u}}\end{array}$ & Chi square $^{t}$ \\
\hline$\overline{\mathrm{A} 08}$ & SCAR & F3 & No & Yes & 0.86 & 0.99 & $11.54^{* * \mathrm{~s}}$ \\
\hline AT1SNPG3H3 & SNP & & Yes & Yes & 0.86 & 0.6 & $55.73^{* *}$ \\
\hline AW14 & SCAR & F3 & No & Yes & 0.86 & 0.99 & $11.38 * *$ \\
\hline $\mathrm{BC} 231$ & SCAR & $\mathrm{F} 7, \mathrm{Y7}$ & Yes & No & 0.86 & & \\
\hline BC523 & SCAR & $\mathrm{F} 1, \mathrm{Y} 2$ & No & Yes & 0.86 & 0.63 & $47.95^{* *}$ \\
\hline BC526 & SCAR & F4,Y6,S4 & No & Yes & 0.86 & 0.95 & $5.24 *$ \\
\hline C1LG3H3 & SNP & & Yes & Yes & 0.86 & 0.73 & $22.54 * *$ \\
\hline C4LG1H2 & SNP & & No & Yes & 0.86 & 0.97 & $9.01 *$ \\
\hline CM07 & EST-SSR & & No & Yes & 0.86 & 0.88 & $0.19 \mathrm{NS}$ \\
\hline CM15 & EST-SSR & & No & Yes & 0.86 & 0.78 & $10.77 * *$ \\
\hline CM21 & EST-SSR & & No & Yes & 0.86 & 0.79 & $19.64 * *$ \\
\hline CM26 & EST-SSR & & No & Yes & 0.86 & 0.81 & $23.08 * *$ \\
\hline CM30 & EST-SSR & & No & Yes & 0.86 & 0.74 & $9.66^{*}$ \\
\hline CM33 & EST-SSR & & No & Yes & 0.86 & 0.88 & $0.13 \mathrm{NS}$ \\
\hline CM49 & EST-SSR & & No & Yes & 0.86 & 0.85 & $0.08 \mathrm{NS}$ \\
\hline $\mathrm{CS} 24$ & EST-SSR & & No & Yes & 0.86 & 0.56 & $51.20 * *$ \\
\hline CS31 & EST-SSR & & No & Yes & 0.86 & 0.61 & $52.59 * *$ \\
\hline CS41 & EST-SSR & & No & Yes & 0.86 & 0.63 & $38.76^{* *}$ \\
\hline CS-AT1 & SCAR & & No & Yes & 0.86 & 0.73 & $10.38^{*}$ \\
\hline CS-PS & GENE & & No & Yes & 0.86 & 0.83 & $0.80 \mathrm{NS}$ \\
\hline CSWACC02 & SSR & & No & Yes & 0.86 & 0.75 & $8.72 *$ \\
\hline CSWATT02 & SSR & & Yes & No & 0.86 & & \\
\hline CSWCT05B & SSR & & No & Yes & 0.86 & 0.62 & $85.87 * *$ \\
\hline CSWCT11 & SSR & Y7 & No & Yes & 0.86 & 0.83 & $2.91 \mathrm{NS}$ \\
\hline CSWCTT02 & SSR & & No & Yes & 0.86 & 0.76 & $16.78^{* *}$ \\
\hline CSWCTT05 & SSR & & No & Yes & 0.86 & 0.76 & $13.26^{* *}$ \\
\hline CSWCTT06 & SSR & & No & Yes & 0.86 & 0.68 & $26.59 * *$ \\
\hline CSWGAAA02 & SSR & & Yes & Yes & 0.86 & 0.74 & $8.95^{*}$ \\
\hline CSWGATT01C & SSR & & No & Yes & 0.86 & 0.75 & $16.56^{* *}$ \\
\hline CSWTA11B & SSR & Y7 & Yes & No & 0.86 & & \\
\hline CSWTAAA01 & SSR & $\mathrm{F} 4, \mathrm{~S} 4$ & Yes & Yes & 0.86 & 0.99 & $11.38^{* *}$ \\
\hline D11SNPG3H1 & SNP & & Yes & Yes & 0.86 & 0.81 & $14.66^{* *}$ \\
\hline F04-21 & SSR & & No & Yes & 0.86 & 0.76 & $12.26^{* *}$ \\
\hline F04-89 & SSR & & No & Yes & 0.86 & 1 & $13.49 * *$ \\
\hline F08-90A & SSR & & No & Yes & 0.86 & 0.64 & $52.09 * *$ \\
\hline M4LH2 & SNP & & Yes & No & 0.86 & & \\
\hline M-5-BE-L & BAC end & & No & Yes & 0.86 & 0.42 & $119.23 * *$ \\
\hline M-6-BE-R & BAC end & & No & Yes & 0.86 & 0.51 & $90.49 * *$ \\
\hline M7LSNPG3H3 & SNP & & No & Yes & 0.86 & 0.57 & $85.68 * *$ \\
\hline M8SNPG1H1 & SNP & F6 & Yes & No & 0.86 & & \\
\hline S_AV14-2 & SCAR & & Yes & No & 0.86 & & \\
\hline S_AV16-3 & SCAR & Y2 & Yes & No & 0.86 & & \\
\hline S_E9 & SCAR & & Yes & No & 0.86 & & \\
\hline S_M5 & SCAR & & Yes & Yes & 0.86 & 0.76 & $6.64 *$ \\
\hline TJ79 & SSR & & No & Yes & 0.86 & 0.85 & $0.11 \mathrm{NS}$ \\
\hline W7SNPG1H3 & SNP & & Yes & Yes & 0.86 & 0.65 & $51.69 * *$ \\
\hline
\end{tabular}

${ }^{\mathrm{z}} \mathrm{BAC}$ end $=$ bacteria artificial chromosome end, EST-SSR $=$ expressed sequence tag simple sequence repeat, GENE $=$ sequenced polymorphic gene, $\mathrm{SCAR}=$ sequence characterized amplified region, $\mathrm{SNP}=$ single nucleotide polymorphism, $\mathrm{SSR}=$ simple sequence repeat.

${ }^{y}$ Linkage groups (LG) F1, F2, F3, F4, F5, F6, and F6 according to Fazio et al. (2003); LG S1, S2, S3, S4, S5, S6, and S7 are from Sun et al. (2006); LG Y1, Y2, Y3, Y4, Y5, Y6, and Y6 according to Yuan et al. (2008).

${ }^{\mathrm{x}} \mathrm{BC}_{1}=$ markers used during the marker-assisted selection of the $\mathrm{BC}_{1}$ generation.

${ }^{\mathrm{w}} \mathrm{IBL}=$ inbred backcross lines, yes $=$ use of that marker during selection or evaluation, no $=$ exclusion of the marker.

${ }^{v}$ Expected allele frequency for homozygous genotype for the recurrent parent of IBL.

"Observed allele frequency for homozygous genotype for the recurrent parent for IBL.

${ }^{t}$ Chi-square analysis with Yate's correction factor $\left\{\sum[\mathrm{ABS}(\mathrm{O}-\mathrm{E})-0.5]^{2} / \mathrm{E}\right\}$ applied to calculations using observed allelic frequencies of the IBL compared with their expected $\mathrm{BC}_{2} \mathrm{~S}_{3}$ allelic frequencies.

${ }^{\mathrm{NS}}, *$, and $* *$ are not significant, $P \leq 0.05$, and $P \leq 0.01$, respectively. 


\section{Results}

Combining ABILITy. In, 2006 and 2007, several parents (females $=$ WI 7012A and WI 1983G; males $=$ WI 7023A, Gy-7, H19, WI 6996A, and WI 7011H) and their $\mathrm{F}_{1}$ progeny were evaluated in the open field for DA, SEX, LBN, FP, and fruit L:D (Table 3). Although the year was not significant for DA, SEX, and LBN $(P \leq 0.05)$, blocks across years differed $(P \leq 0.05)$ for all traits, except yield and L:D. DA was the only trait that did not differ among lines $(P \leq 0.05)$. Moreover, yearby-line interactions were detected for all traits $(P \leq 0.01)$.

GCA and SCA for each parental line are given in Table 4. Lines Gy-7 and WI 7023A exhibited the best GCA for SEX in which a positive GCA correlates to a gynoecious plant and a negative GCA for SEX correlates to a monoecious plant. Lines with a positive GCA for LBN had a greater number of
LBN per plant. Lines WI $7011 \mathrm{H}$ and $\mathrm{H} 19$ had the highest positive GCA for LBN. Likewise, lines with positive GCA values for FP had a greater number of fruit. Line WI $7011 \mathrm{H}$ had the highest positive GCA value for FP. However, lines with a more favorable DA had negative values because they flowered earlier. The greatest GCA for DA was detected in progeny derived from WI 1983G. Lines with moderate GCA values for L:D were favorable because the desired fruit is neither too short and fat nor too long and skinny. The most extreme GCA for L:D were detected in lines WI 7012A (long and skinny) and WI 1983G (short and wide), respectively. Although the overall SCA for SEX was positive, exceptions were detected in crosses between WI $1983 \mathrm{G}$ with H19, WI 6996A with WI 7012A, and WI 7012A with H19. The worst SCA for SEX was identified in WI 7012A $\times$ H19 progeny. While the highest SCA for LBN was detected in cross progeny

Table 3. Analysis of variance of morphological traits in U.S. processing cucumber defined by parental and cross-progeny performance as evaluated by a North Carolina Design II mating scheme at Hancock, WI, in 2006 and 2007.

\begin{tabular}{|c|c|c|c|c|c|c|c|c|c|c|}
\hline \multirow[b]{2}{*}{ Variable } & \multicolumn{2}{|c|}{$\mathrm{DA}^{\mathrm{z}}$} & \multicolumn{2}{|c|}{$\mathrm{SEX}^{\mathrm{y}}$} & \multicolumn{2}{|c|}{$\mathrm{LBN}^{\mathrm{x}}$} & \multicolumn{2}{|c|}{ Avg yield ${ }^{w}$} & \multicolumn{2}{|c|}{ Avg L:Dv } \\
\hline & $\overline{\mathrm{df}^{\mathrm{u}}}$ & $\mathrm{F}$ & $\overline{\mathrm{df}}$ & $\mathrm{F}$ & $\overline{\mathrm{Df}}$ & $\mathrm{F}$ & $\mathrm{df}$ & $\mathrm{F}$ & $\overline{\mathrm{df}}$ & $\mathrm{F}$ \\
\hline$\overline{\text { Year }}$ & 1 & $2.61 \mathrm{NS}^{\mathrm{t}}$ & 1 & $3.00 \mathrm{NS}$ & 1 & $0.00 \mathrm{NS}$ & 1 & $28.74 * *$ & 1 & $298.57 * *$ \\
\hline Block & 6 & $4.10 * *$ & 6 & $2.25 *$ & 6 & $5.49 * *$ & 6 & $0.66 \mathrm{NS}$ & 6 & $0.59 \mathrm{NS}$ \\
\hline Year-by-line & 17 & $4.10 * *$ & 17 & $42.77 * *$ & 17 & $27.52 * *$ & 17 & $5.74 * *$ & 17 & $4.88 * *$ \\
\hline
\end{tabular}

${ }^{\mathrm{z}}$ Days to anthesis recorded as the number of days between sowing and the appearance of the first fully expanded corolla.

y Sex expressions were gynoecious, predominately female, and monoecious plants and were given values of 2,1 , and 0 , respectively.

${ }^{x}$ Lateral branch number recorded as number of lateral branches within the first 10 nodes of individual plants.

${ }^{\mathrm{w}}$ Average number of fruit per plant over five harvests.

${ }^{v}$ Average fruit length:diameter ratio averaged over five harvests.

"Numerator df.

t*,**, NS indicate significance at $P \leq 0.05, P \leq 0.01$, and not significant, respectively.

Table 4. General combining ability and specific combining ability analyses for yield component traits in U.S. processing cucumber lines evaluated by a North Carolina Design II mating scheme at Hancock, WI, in 2006 and 2007.

\begin{tabular}{|c|c|c|c|c|c|c|c|}
\hline & $\begin{array}{l}\text { Market } \\
\text { class }^{z}\end{array}$ & Crosses & $\mathrm{DA}^{\mathrm{y}}$ & SEX $^{\mathrm{x}}$ & $\mathrm{LBN}^{\mathrm{w}}$ & Avg yield ${ }^{v}$ & $\operatorname{Avg} L: D^{u}$ \\
\hline \multirow{5}{*}{$\begin{array}{l}\text { General combining } \\
\text { ability }\end{array}$} & USP & WI $1983 \mathrm{G}$ & -0.36 & 0.22 & -0.14 & -0.01 & -0.14 \\
\hline & USP & WI 6996A & -0.08 & 0.07 & -0.1 & -0.1 & 0 \\
\hline & USP & Gy-7 & 0.42 & 0.27 & -0.37 & 0.13 & 0.02 \\
\hline & USP & H19 & 0.05 & -0.84 & 0.33 & -0.39 & 0.08 \\
\hline & USP & WI $7011 \mathrm{H}$ & -0.26 & 0.23 & 0.39 & 0.23 & -0.09 \\
\hline \multirow{6}{*}{$\begin{array}{l}\text { Specific combining } \\
\text { ability }\end{array}$} & USP & WI 1983G × WI 6996A & 0.14 & 0.15 & -0.11 & -0.03 & -0.18 \\
\hline & USP & WI $1983 G \times$ WI 7023A & 0.51 & 0.15 & -0.19 & 0.2 & -0.15 \\
\hline & USP & WI $1983 \mathrm{G} \times \mathrm{Gy}-7$ & 0.01 & 0.15 & -0.78 & -0.17 & -0.09 \\
\hline & USP & WI $1983 G \times H 19$ & 0.64 & -0.11 & 0.25 & -0.23 & -0.06 \\
\hline & USP & WI $7011 \mathrm{H} \times$ WI $1983 \mathrm{G}$ & 0.51 & 0.15 & 0.14 & 0.14 & -0.29 \\
\hline & HYS & WI $7011 \mathrm{H} \times$ WI 7012A & -0.74 & 0.09 & 0.65 & 0.33 & 0.08 \\
\hline
\end{tabular}

${ }^{\mathrm{z} U S P}=$ two U.S. processing lines matings, HYS $=$ U.S. processing line mating with the $C$. hytivus derivative.

${ }^{\mathrm{y}}$ Days between sowing and the appearance of the first fully expanded corolla.

${ }^{\mathrm{x}}$ Sex expressions were gynoecious, predominately female, and monoecious plants and were given values of 2,1 , and 0 , respectively.

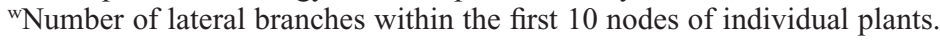

${ }^{\mathrm{v}}$ Average number of fruit per plant over five harvests.

"Fruit length:diameter ratio averaged over five harvests. 
derived from lines WI 7011H and WI 7012A, the highest SCA for DA and FP was identified in progeny derived from $1983 \mathrm{G} \times$ H19 and Gy-7 × 7012A matings, respectively. Likewise, the highest and lowest SCA for L:D was detected in progeny derived from crosses between WI 7012A with H19 and WI $1983 \mathrm{G}$ with WI $7011 \mathrm{H}$, respectively.

Phenotypic evaluation of IBL. An ANOVA partitioning main effects (planting date, block within planting, and line) and interactions (planting-by-line interaction) for DA, SEX, LBN, leaf size, L:D, and FP is presented in Table 5. Planting date did not significantly affect SEX, leaf size, and FP. Likewise, SEX and L:D did not differ significantly across blocks within a planting $(P \leq 0.05)$. Although IBL differed significantly in all traits, only L:D did not differ significantly across plantings $(P \leq 0.05)$.

The IBL rankings between plantings for all the traits examined were significant $[P \leq 0.01$ (Table 5)]. With rare exception, visual analysis of mean trait rankings suggests the rank relationships of IBL were similar across planting dates (Delannay, 2009).

The variance estimates by planting date, block within planting and line, as well as trait repeatability measures are given in Table 6 for DA, SEX, LBN, leaf size, L:D, and FP. Repeatability measures were interpreted as significant for all traits because their values were at least twice that of their standard errors (Hallauer and Miranda, 1988). Repeatability was highest for SEX $(0.99 \pm 0.14)$ and leaf size $(0.91 \pm 0.14)$. Moderate repeatability of measurements were detected for DA $(0.65 \pm 0.11), \mathrm{LBN}(0.51 \pm 0.10), \mathrm{FP}(0.45 \pm 0.18)$, and L:D $(0.32 \pm 0.14)$.

PC 1 through 3 accounted for $67.1 \%$ of the variation among the IBL evaluated [PC 1 (25.1\%), PC 2 (22.2\%), and PC 3 (19.8\%)] (Fig. 2). While FP and LBN accounted for most of the variation within PC 1, DA and SEX accounted for the variation defined by PC 2 . In contrast, the phenotypic variation defined by PC 3 was based on similar contributions by all the traits examined (Fig. 2). While grouping of IBL by their FP and LBN is defined along PC 1 , grouping in PC 2 is characterized by the SEX and DA of IBL. Leaf size and fruit L:D did not contribute substantially to the ordination of IBL in PC 1 and PC 2 (Fig. 2).

Three IBL $(20,36$, and 58) with unique ordinations after PCA possess little leaves (Fig. 2). The remaining IBL clustered in between parental lines WI 7023A and WI 7012A after PCA. The IBL located near WI 7023A are gynoecious, possess comparatively few lateral branches, and bear fruit having relatively small L:D ratios. The IBL located in close proximity to line WI 7012A are relatively high yielding, possess many lateral branches, and develop relatively narrow, long fruit.

Genotypic evaluation. The expected gene frequencies for IBL homozygous for recurrent parent (AA), heterozygous (Aa), and homozygous for donor parent (aa) alleles are 0.86, 0.03,

Table 5. Yield component traits evaluated in U.S. pickling cucumber inbred backcross lines evaluated in the open field in two plantings at Hancock, WI, in 2008.

\begin{tabular}{|c|c|c|c|c|c|c|c|c|c|}
\hline \multirow[b]{2}{*}{ Trait $^{z}$} & \multicolumn{2}{|c|}{ Planting } & \multicolumn{2}{|c|}{ Block } & \multicolumn{2}{|c|}{ Line } & \multicolumn{2}{|c|}{ Planting-by-line } & \multirow[b]{2}{*}{ Correlation $^{y}$} \\
\hline & $\mathrm{df}$ & $\mathrm{F}$ & $\mathrm{df}$ & $\mathrm{F}$ & $\mathrm{df}$ & $\mathrm{F}$ & $\mathrm{df}$ & $\mathrm{F}$ & \\
\hline$\overline{\mathrm{DA}}$ & 1 & $36.62 * * x$ & 4 & $5.30 * *$ & 97 & $7.04 * *$ & 93 & $2.67 * *$ & $0.71 * *$ \\
\hline SEX & 1 & $0.02 \mathrm{NS}$ & 4 & $1.09 \mathrm{NS}$ & 97 & $84.37 * *$ & 93 & $1.63 * *$ & $0.95 * *$ \\
\hline Leaf size & 1 & $1.04 \mathrm{NS}$ & 4 & $4.71 * *$ & 97 & $10.87 * *$ & 93 & $11.42 * *$ & $1.00 * *$ \\
\hline Avg yield & 1 & $0.02 \mathrm{NS}$ & 4 & $3.95 * *$ & 97 & $3.44 * *$ & 97 & $1.45^{* *}$ & $0.40 * *$ \\
\hline Avg L:D & 1 & $5.35^{*}$ & 4 & $2.09 \mathrm{NS}$ & 97 & $12.27 * *$ & 97 & $0.98 \mathrm{NS}$ & $0.59 * *$ \\
\hline
\end{tabular}

${ }^{\mathrm{z}} \mathrm{DA}=$ days between transplanting and the appearance of the first fully expanded corolla; SEX $=$ sex expressions were gynoecious, predominately female, and monoecious recorded with values of 2,1 , and 0 , respectively; LBN = number of lateral branches on the first 10 nodes; Leaf size = percentage of plants within a line to with a $l l$ phenotype with a maximum leaf area of 30 to $40 \mathrm{~cm}^{2}$; Avg yield $=$ average number of fruit per plant within a line over three harvests; Avg L:D = average length:diameter ratio of 5 to 10 fruit per plot over three harvests.

yPearson rank correlations among morphological traits evaluated in the open field.

$\mathrm{x} * * *$, NS indicate significance at $P \leq 0.05, P \leq 0.01$, and not significant, respectively.

Table 6. Variance estimates and repeatability measures, and their standard errors for morphological traits within cucumber inbred backcross lines evaluated in the open field in two planting dates during 2008 at Hancock, WI.

\begin{tabular}{|c|c|c|c|c|c|c|c|c|c|c|}
\hline \multirow[b]{2}{*}{ Trait $^{z}$} & \multicolumn{2}{|c|}{ Planting } & \multicolumn{2}{|c|}{ Replication } & \multicolumn{2}{|c|}{ Line } & \multicolumn{2}{|c|}{ Planting by Line } & \multicolumn{2}{|c|}{ Repeatability } \\
\hline & Estimate $^{y}$ & $\mathrm{SE}^{\mathrm{x}}$ & Estimate & $\mathrm{SE}$ & Estimate & SE & Estimate & $\mathrm{SE}$ & Estimate & $\begin{array}{c}\mathrm{SE} \\
\end{array}$ \\
\hline$\overline{\mathrm{DA}}$ & 1.62 & 2.36 & 0.08 & 0.07 & 4.85 & 0.83 & 0.96 & 0.24 & 0.65 & 0.11 \\
\hline SEX & 0 & 0 & 0 & 0 & 0.76 & 0.11 & 0.01 & 0 & 0.99 & 0.14 \\
\hline Little-sized leaf & 0 & 0 & 0 & 0 & 0.03 & 0 & 0 & 0 & 0.91 & 0.14 \\
\hline Avg yield & 0 & 0 & 0.01 & 0.01 & 0.1 & 0.04 & 0.11 & 0.04 & 0.45 & 0.18 \\
\hline Avg L:D & 0 & 0.01 & 0 & 0 & 0.05 & 0.02 & 0.09 & 0.02 & 0.32 & 0.14 \\
\hline
\end{tabular}

${ }^{\mathrm{z}} \mathrm{DA}=$ days between transplanting and the appearance of the first fully expanded corolla; SEX $=$ sex expressions were gynoecious, predominately female, and monoecious recorded with values of 2, 1 , and 0 , respectively; LB = number of lateral branches on the first 10 nodes; LL $=$ percentage of plants within a line with a maximum leaf area of 30 to $40 \mathrm{~cm}^{2}$; Avg yield = average number of fruit per plant within a line over three harvests; Avg L:D = average length:diameter ratio of 5 to 10 fruit per plot over three harvests.

${ }^{y}$ Estimate of variance or repeatability.

${ }^{\mathrm{x}} \mathrm{SE}$ of variance estimate. 


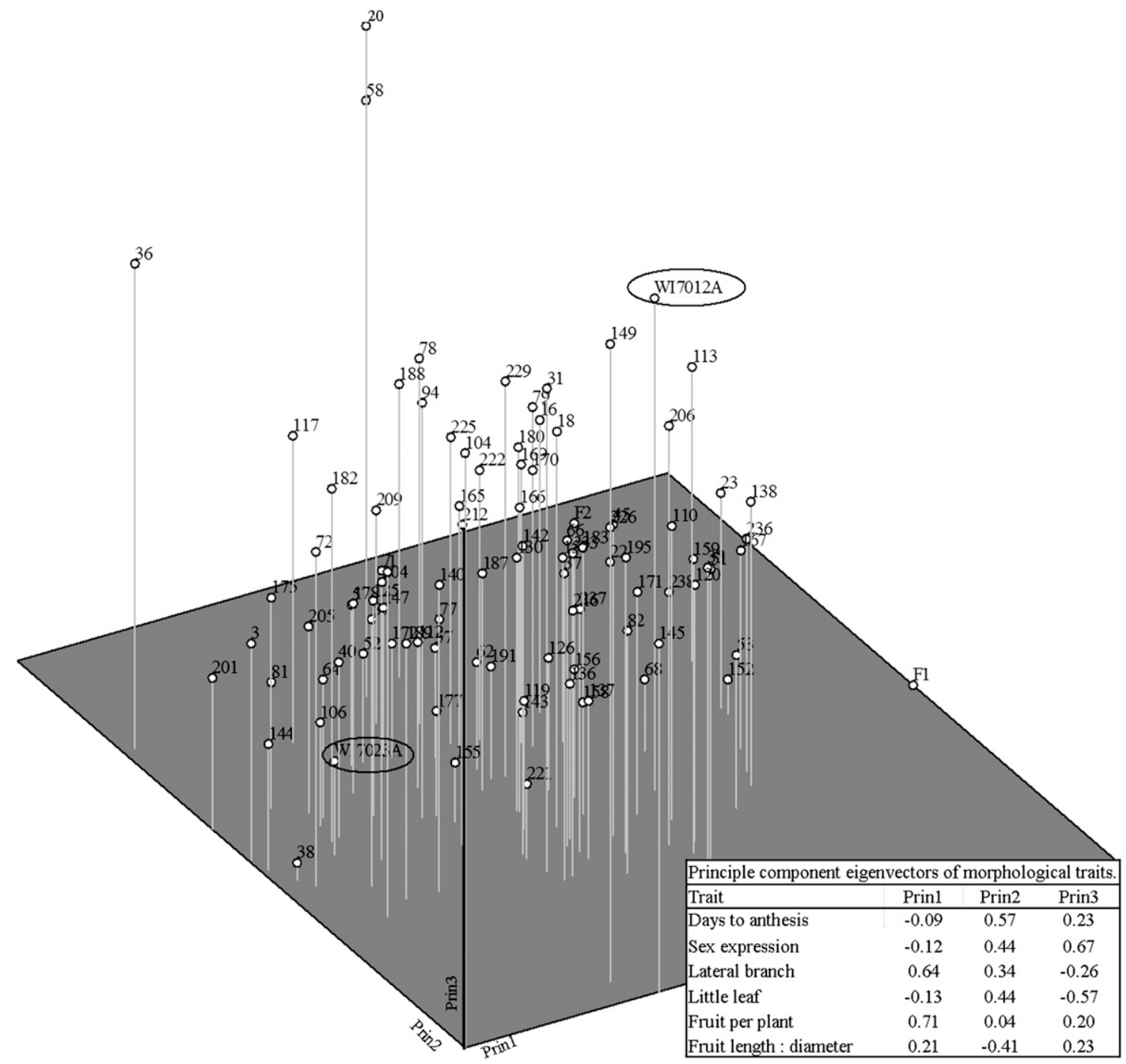

Fig. 2. Genetic relationships of U.S. processing cucumber parental lines WI $7023 \mathrm{~A}$ and Cucumis sativus $\times$ Cucumis hystrix-derived WI $7012 \mathrm{~A}$, their $\mathrm{F}_{1}$ and $\mathrm{F}_{2}$ progeny, and inbred backcross lines (94) after principle component analysis as framed by morphological traits observed in the open-field in 2008 at Hancock, WI

and 0.11 , respectively (Table 2). Thirty-two of the 38 codominant markers $(84 \%)$ deviated from marker frequencies anticipated for a $\mathrm{BC}_{2} \mathrm{~S}_{3}$ population, and thus homogeneity tests indicated that the frequency of alleles at the loci examined were not uniform in this generation.

Ten of 47 markers used in the project were previously mapped by Fazio et al. (2003), Sun et al. (2006), or Yuan et al. (2008). Markers were found in all linkage groups according to the Fazio et al. map (2003), with the exception of linkage groups 2 and 5 (Table 2).

The relationship depiction of IBL after MDS (Fig. 3) was supported by a relatively low stress value (0.31), where the ordination of C. hystrix and line WI 7012A fell outside the clustered grouping of IBL. The most genetically similar IBL were lines 113 and 201, and lines 3 and $180(\mathrm{GD}=0.16)$. In contrast, IBL with the least genetic affinity were lines 51 and $187(\mathrm{GD}=0.75)$. Although $C$. hystrix predictably possessed little genetic affinity to any of the IBL examined $(\mathrm{GD}=0.67)$, WI 7012A possessed, on average, less genetic affinity to the IBL than to $C$. hystrix $(\mathrm{GD}=0.74)$.

\section{Discussion}

The development of IBL reported herein provides unique germplasm that can be used directly by plant improvement programs seeking to increase genetic diversity in cucumber. The source of this genetic diversification in WI 7012A is novel because it originates from germplasm (C. sativus $\times$ C. hytivus) that possesses genomic contributions from $C$. hystrix, which lies outside the primary gene pool of cucumber. Moreover, C. hystrix houses resistance to important diseases not presently found in cucumber (i.e., virus and gummy stem blight) (Chen et al., 2003), and the C. hytivus-derived $\mathrm{BC}_{1} \mathrm{~S}_{3}$ line WI 7012A possesses high yield potential because of the number of lateral branches it bears (about three as described herein).

Evaluation of THE COMBINING ABILITY OF C. HYTIVUSDERIVED GERMPLASM. Parental lines $1983 \mathrm{G}$ and WI 7012A were chosen as maternal parents for the combining ability because they represent distinct and unrelated pedigrees and they possess contrasting horticultural characteristics. Gynoecious U.S. pickling line $1983 \mathrm{G}$ originates from the USDA cucumber breeding 


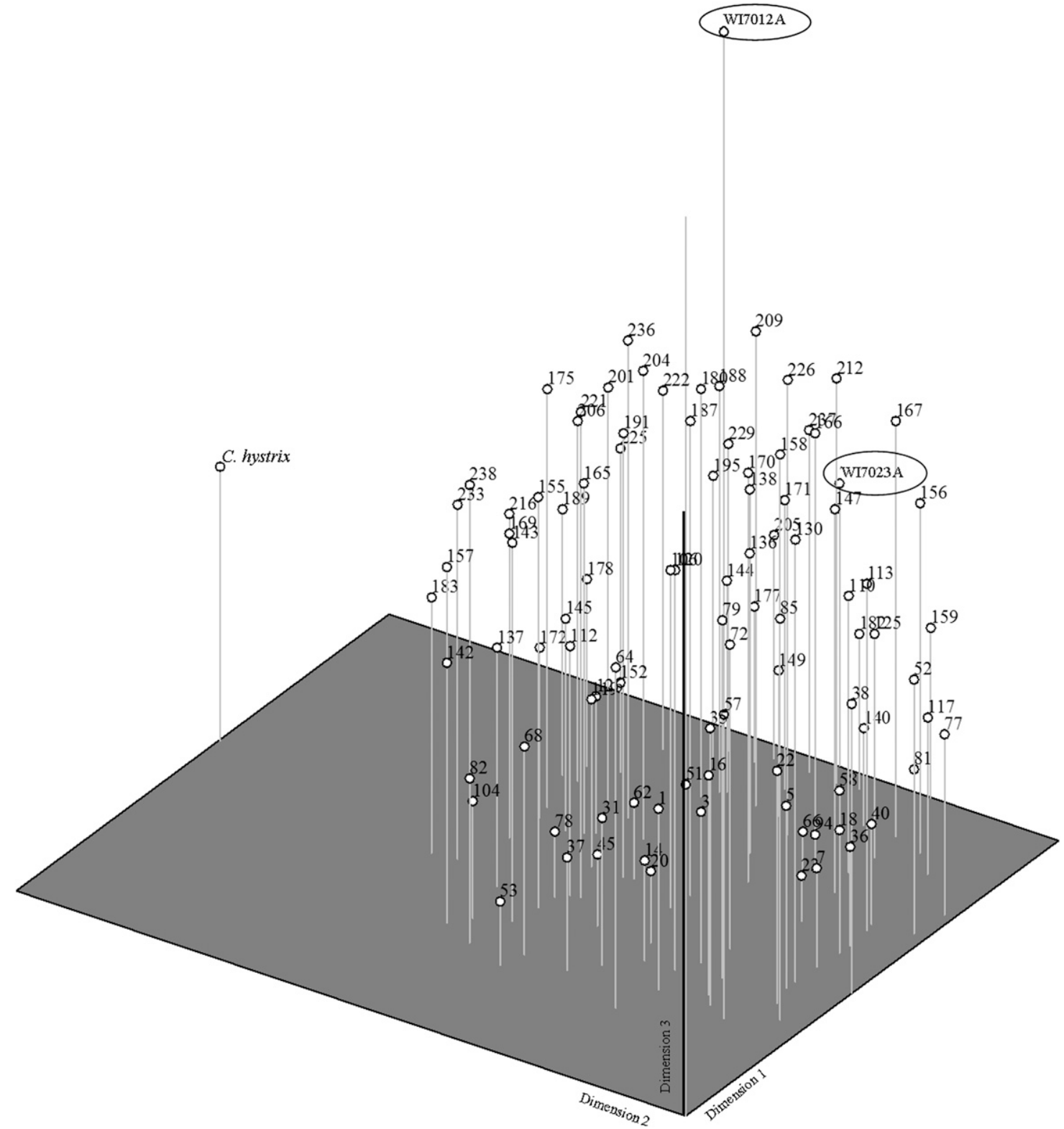

Fig. 3. Genetic relationships among U.S. processing cucumber parental line WI 7023A and Cucumis sativus $\times$ Cucumis hystrix-derived WI $7012 \mathrm{~A}$, and a diverse set of 94 inbred backcross lines after multidimensional scaling as framed by Rogers genetic distances (Rogers, 1972), modified by Wright (1978), as defined by 37 marker loci.

program and has substantial percentages of Gy-14 (Clemson University, Clemson, SC) in its pedigree (Peterson et al., 1986). In stark contrast, the late flowering monoecious line WI 7012A is derived from the amphidiploid C. hytivus and contains substantial percentages $(>75 \%)$ of the Chinese cultivar Beijingjietou in its genetic background.

Predictably, hybrid progeny derived from WI 7012A tended to produce a high frequency of lateral branches (average $=2.5$ ). These progeny bore more fruit than hybrid progeny derived from $1983 \mathrm{G}$, which were, with rare exception (i.e., $1983 \times$ H19), early flowering and gynoecious, and possessed comparatively few lateral branches and fruit (Table 4).

RELATIVE BREEDING VALUE OF TRAITS. In the upper-midwestern U.S., the timing of cucumber harvest in production fields is often staggered into two or more plantings 1 to 4 weeks apart to distribute labor activities and reduce production management risk. Typically, germination, emergence, and plant growth in early plantings (May to mid-June) can be dramatically affected by climatic conditions. Although plant development is less affected by fluctuations in climatic conditions in later plantings (mid-June to early-July), cooler temperatures can reduce harvest potential in late harvests (late August to early September). Plantings of the study reported herein are considered early and late, where growing conditions were dissimilar. The early planting had above normal rainfall $(14.3 \mathrm{~cm})$, relative humidity $=71.5 \%$, and wind gusts at about $25 \mathrm{~km} \cdot \mathrm{h}^{-1}$, whereas the late planting had below normal rainfall $(7.3 \mathrm{~cm})$, relative humidity $=70.6 \%$, and moderate wind gusts at about $13 \mathrm{~km} \cdot \mathrm{h}^{-1}$.

The early planting suffered seedling damage caused by strong winds and heavy rains, which delayed maturity. Yield differences, however, were not detected between plantings, which indicate that plants recovered from the observed damage 
experienced at early growth stages (Table 5). In fact, the fruit yields of progeny with WI 7012A in their pedigree were consistently moderate to high (Delannay, 2009). The vines of line WI 7012A were vigorous (visual observation), and this characteristic was inherited by its hybrid progeny [i.e., comparatively high LBN (Table 3)]. This characteristic likely provided a harvest advantage, especially in late September harvests. Moreover, although SEX and L:D are affected by abiotic and biotic stresses (Fazio et al., 2003; Rudich et al., 1972), variability for these traits was not detected across treatment blocks (Table 5). Although L:D was the only trait for which genotype-by-environment interaction was not displayed in cross progeny, differences detected in other traits were of magnitude only, and line performance ranking remained relatively consistent across test environments (Table 5).

Trait stability within and among growing environments increases selection efficacy, and resulting selections often possess a myriad of contrasting phenotypic characteristics. In this study, the $\mathrm{BC}_{2}$-evaluated progeny differed to some degree in all of the traits examined, thus, resulting IBL were genotypically and phenotypically diverse. It is clear that marker-based selection for heterozygosity at $\mathrm{BC}_{1}$ did not eliminate the phenotypic diversity in $\mathrm{BC}_{2}$ progeny. Moreover, given the high repeatability measures for SEX, leaf size, fruit $\mathrm{L}: \mathrm{D}$, and FP, and moderate repeatability of DA and LBN (Table 6), the IBL developed herein should perform consistently in early and late harvest operations typical of climates in the uppermidwestern U.S.

Morphological Diversity Within IBL. The leaf size of three IBL $(20,36$, and 58) were diminutive $(l l)$, and thus were phenotypically distinct from other IBL (Fig. 2). Although IBL 72 and 140 segregated for leaf size, little-leaf variants in these IBL did not differ morphologically from the majority of the IBL. The little-leaf type is associated with multiple lateral branching and sequential fruiting not present in commercial cucumber (Fazio et al., 2003), thus, this genotype has potential for increasing yield in cucumber (Serquen et al., 1997). However, the little-leaf trait is often also associated with poor fruit quality (i.e., bloating, carpel separation, and placental hollows) and for this reason has not been used extensively in commercial production operations. The multiple branching and sequential fruit habit is also present in C. sativus var. hardwickii, C. hystrix, C. hytivus, and C. hytivus-derived WI 7012A (Chen et al., 1997; Staub and Kupper, 1985; data presented herein). While poor interior fruit quality is associated with C. sativus var. hardwickii, WI 7012A and its derived crossprogeny possess acceptable interior fruit quality (Delannay, 2009). These characteristics and its vigorous plant architecture make WI 7012A and IBL with similar characteristics attractive to plant-improvement programs whose goals are to increase yield potential in commercial cucumber.

With the exception of three little-leaf IBL, no phenotypically distinct groups of IBL were identified [i.e., PCA places IBL between parental lines WI 7023A and WI 7012A (Fig. 2)]. This is in contrast to studies of IBL in Beit Alpha and European Long cucumber (Delannay, 2009; Delannay and Staub, 2010) in which a subset of IBL deviated from the cluster of IBL present in graphical depictions after PCA. Nevertheless, extreme IBL for each trait did ordinate toward the exterior of the central cluster of IBL herein. For instance, IBL 206 develops the greatest number of fruit per plant (about four) and lateral branches (about four) of the IBL evaluated (Fig. 2). In contrast, IBL 3 provided the lowest yield (about one fruit per plant), IBL 38 the lowest L:D (2.6), and IBL 188 required the longest time to flower $(\mathrm{DA}=$ about $50 \mathrm{~d})$. By comparison, IBL 119 recorded the shortest time to flower (DA = about 39 d) and IBL 226 developed fruit with the largest L:D (about 3.9). Those IBL that were positioned to the periphery of the PCA projection must be regarded as most diverse, and should be considered for inclusion in plant-improvement programs whose objective is to increase genetic diversity.

GenetiC Diversity of IBL. Molecular polymorphisms were used to determine genetic affinities between IBL. All IBL grouped near the recurrent parent after multidimensional scaling [WI 7023A (Fig. 3)]. The C. hystrix accession evaluated was genetically unique when compared with all IBL and the C. hytivus-derived parental line WI 7012A. Nine of the 37 markers (24\%; CM15, CM55, CS24, CSWACC02, CSWGATT01C, D11SNPG3H1, F04-21, F05-75, and TJ79) used in the final IBL genotyping defined polymorphisms unique to $C$. hystrix. None of these polymorphisms was found in the C. hytivus-derived WI 7012A, which supports a previous finding in which SSR alleles unique to $C$. hystrix were not detected in the derived amphidiploid C. hytivus (Zhou et al., 2009). Curiously, in the same study, introgression of the $C$. hystrix genome was detected in C. hytivus using AFLP markers. This suggests that even though much of the $C$. hystrix genome is lost during backcross introgression leading to $C$. hytivus, rather small, vestigial segments of the genome are likely retained in C. hytivus and perhaps in its offspring (e.g., IBL). However, due to the backcrossing involved in the formation of the C. hytivus derivative (WI 7012A) and subsequently the IBL, these vestigial segments may be comparatively scarce in IBL.

The genotypic and phenotypic diversity of these IBL are not necessarily equivalent. For example, although IBL 113 and 201 possess the strongest genetic affinities $(\mathrm{GD}=0.16)$, they had dramatically different morphological attributes (Fig. 2). For example, IBL 113 produces many lateral branches and many narrow fruit (about four laterals per plant, 3.4 fruit per plant, and $\mathrm{L}: \mathrm{D}=3.4$ ), IBL 201 produces few lateral branches and comparatively few short fruit (0 to 1 laterals per plant, 1 to 2 fruit per plant, and L:D $=2.7$ to 2.9 ). Thus, even though much of the genomic diversity unique to $C$. hystrix was lost during the development of line WI 7012A, novel attributes of this parental line were evident in IBL (i.e., multiple lateral branching, sequential fruiting, FP, and L:D). Moreover, many of these IBL are gynoecious and lack the negative attributes associated with the monoecious WI 7012A (i.e., spiny, warty, and oblong fruit).

A genetically diverse array of $C$. hytivus-derived IBL in a U.S. processing cucumber genetic background was created herein upon which no phenotypic selection was practiced. Yield and quality component trait evaluation indicated that considerable phenotypic diversity exists among the IBL. Thus, these MAS-derived IBL will likely be valuable in developing advanced genetic stocks for elucidation of gene action and epitasis [e.g., multiple lateral branching (Robbins et al., 2008)]. Additionally, IBL differing in unique phenotypic attributes ( $l l$ vs. $L L$, determinate vs. indeterminate, and unilateral vs. multiple lateral branching) could be used to elucidate physiological mechanisms (e.g., disease resistance and abiotic stress tolerance) (Secre and Staub, 1999). Last, because of their unique germplasm and the manner in which the IBL were 
developed, these IBL will provide cucumber breeders with much needed diverse germplasm.

\section{Literature Cited}

Chen, J.F., J.W. Adelberg, J.E. Staub, H.T. Skorupska, and B.B. Rhodes. 1998. A new synthetic amphidiploid in Cucumis from C. sativus $\mathrm{L} \times$ C. hystrix Chakr. F1 interspecific hybrid, p. 336339. In: J.D. McCreight (ed.). Cucurbitaceae-98: Evaluation and enhancement of cucurbit germplasm. ASHS Press, Alexandria, VA. Chen, J.F. and J.H. Kirkbride. 2000. A new synthetic species of Cucumis (Cucurbitaceae) from interspecific hybridization and chromosome doubling. Brittonia 52:315-319.

Chen, J., J. Staub, C. Qian, J. Jiang, X. Luo, and F. Zhuang. 2003. Reproduction and cytogenetic characterization of interspecific hybrids derived from Cucumis hystrix Chakr. $\times$ Cucumis sativus $\mathrm{L}$. Theor. Appl. Genet. 106:688-695.

Chen, J.F., J.E. Staub, Y. Tashiro, S. Isshiki, and S. Miyazaki. 1997. Successful interspecific hybridization between Cucumis sativus L. and C. hystrix Chakr. Euphytica 96:413-419.

Chung, S.M., J.E. Staub, and J.F. Chen. 2006. Molecular phylogeny of Cucumis species as revealed by consensus chloroplast SSR marker length and sequence variation. Genome 49:219-229.

Delannay, I.Y. 2009. Use of molecular markers to increase genetic diversity of Beit Alpha, European Long, and U.S. Processing market classes of cucumber (Cucumis sativus L.) through marker-assisted selection. PhD Diss., Univ. Wisconsin, Madison.

Delannay, I.Y. and J.E. Staub. 2010. Use of molecular markers aids in the development of diverse inbred backcross lines in Beit Alpha cucumber (Cucumis sativus L.). Euphytica (in press).

Dijkhuizen, A., W.C. Kennard, M.J. Havey, and J.E. Staub. 1996. RFLP variation and genetic relationships in cultivated cucumber. Euphytica 90:79-87.

Falconer, D.S. and T.F.C. Mackay. 1989. Introduction to quantitative genetics. Benjamin Cummings, San Francisco.

Fan, Z., M.D. Robbins, and J.E. Staub. 2006. Population development by phenotypic selection with subsequent marker-assisted selection for line extraction in cucumber (Cucumis sativus L.). Theor. Appl. Genet. 112:843-855.

Fazio, G., J.E. Staub, and S.M. Chung. 2002. Development and characterization of PCR markers in cucumber (Cucumis sativus L.). J. Amer. Soc. Hort. Sci. 127:545-557.

Fazio, G., J.E. Staub, and M.R. Stevens. 2003. Genetic mapping and QTL analysis of horticultural traits in cucumber (Cucumis sativus L.) using recombinant inbred lines. Theor. Appl. Genet. 107:864-874.

Hallauer, A.R. and J.B. Miranda. 1988. Quantitative genetics in maize breeding. 2nd ed. Wiley, Hoboken, NJ.

Harlan, J.R. and J.M. de Wet. 1971. Toward a rational classification of cultivated plants. Taxon 20:509-517.

Harlan, J.R., J.M. de Wet, and E.G. Price. 1973. Comparative evolution of cereals. Evolution 27:311-325.

Horejsi, T. and J.E. Staub. 1999. Genetic variation in cucumber (Cucumis sativus L.) as assessed by random amplified polymorphic DNA. Genet. Resources Crop Evol. 46:337-350.

Kong, Q., C. Xiang, and Z. Yu. 2006. Development of EST-SSRs in Cucumis sativus from sequence database. Mol. Ecol. Notes 6:1234-1236.

Meglic, V., F. Serquen, and J.E. Staub. 1996. Genetic diversity in cucumber (Cucumis sativus L): 1. A reevaluation of the U.S. germplasm collection. Genet. Resources Crop Evol. 43:533-546.

Meglic, V. and J.E. Staub. 1996. Genetic diversity in cucumber (Cucumis sativus L): 2. An evaluation of selected cultivars released between 1846 and 1978. Genet. Resources Crop Evol. 43: $547-558$.

Miliki, A., J.E. Staub, Z.Y. Sun, and A. Ghorbel. 2003. Genetic diversity in African cucumber (Cucumis sativus L.) provides potential for germplasm enhancement. Genet. Resources Crop Evol. 50:461468 .
Nam, Y.W., J.R. Lee, K.H. Song, M.K. Lee, M.D. Robbins, S.M. Chung, J.E. Staub, and H.B. Zhang. 2005. Construction of two BAC libraries from cucumber (Cucumis sativus L.) and identification of clones linked to yield component quantitative trait loci. Theor. Appl. Genet. 111:150-161.

Owens, K.W., F.A. Bliss, and C.E. Peterson. 1985. Genetic variation within and between two cucumber populations derived via the inbred backcross line method. J. Amer. Soc. Hort. Sci. 110:437-441.

Pearson, K. 1900. On a criterion that a given system of deviations from the probable in the case of a correlated system of variables is such that it can be reasonably supposed to have arisen from random sampling. Cambridge University Press, Cambridge, UK.

Peterson, C.E., J.E. Staub, P.H. Williams, and M.J. Palmer. 1986. Wisconsin, 1983 cucumber. HortScience 21:1082-1083.

Ritschel, P., T. de Lima Lins, R. Tristan, G. Cortopassi-Buso, J. Amauri-Buso, and M. Ferreira. 2004. Development of microsatellite markers from an enriched genomic library for genetic analysis of melon (Cucumis melo L.). BMC Plant Biol. 4:9.

Robbins, M.D., M.D. Casler, and J.E. Staub. 2008. Pyramiding QTL for multiple lateral branching in cucumber using nearly isogenic lines. Mol. Breed. 22:131-139.

Rogers, J.S. 1972. Measures of genetic similarity and genetic distance. Studies in Genet. VII. Univ. Texas Publ. 7213:145-153.

Rohlf, F.J. 1998. NTSYS-Pc v2.0. Numerical taxonomy and multivariable analysis system. Applied Biostatistics, New York.

Rudich, J., A.H. Halevy, and N. Kedar. 1972. Ethylene evolution from cucumber plants as related to sex expression. Plant Physiol. 49:998-999.

Secre, S. and J.E. Staub. 1999. Nearly isogenic cucumber genotypes differing in leaf size and plant habit exhibit differential response to water stress. J. Amer. Soc. Hort. Sci. 124:358-365.

Serquen, F.C., J. Bacher, and J.E. Staub. 1997. Genetic analysis of yield components in cucumber at low plant density. J. Amer. Soc. Hort. Sci. 122:522-528.

Staub, J.E., L.K. Crubaugh, and G. Fazio. 2002. Cucumber inbred lines. Cucurbit Genet. Coop. Rpt. 25:1-2.

Staub, J.E., L. Fredick, and T. Marty. 1987. Electrophoretic variation in cross-compatible wild diploid species of Cucumis. Can. J. Bot. 65:792-798.

Staub, J.E., L.D. Knerr, D.J. Holder, and B. May. 1992a. Phylogenetic relationships among several African Cucumis species. Can. J. Bot. 70:509-517.

Staub, J.E., L.D. Knerr, and H.J. Hopen. 1992b. Plant density and herbicides affect cucumber productivity. J. Amer. Soc. Hort. Sci. 117:48-53.

Staub, J.E. and R.S. Kupper. 1985. Results of the use of Cucumis sativus var. hardwickii germplasm following backcrossing with Cucumis sativus var. sativus. HortScience 20:436-438.

Staub, J.E., C.E. Peterson, L.K. Crubaugh, and M.J. Palmer. 1992c. Cucumber population WI 6383 and derived inbreds WI 5098 and WI 5551. HortScience 27:1340-1341.

Staub, J.E., M.D. Robbins, and T.C. Wehner. 2008. Cucumber, p. 241282. In: J. Prohens and F. Nuez (eds.). Vegetables I: Asteraceae, Brassicaceae, Chenopodiaceae, and Cucurbitaceae. Springer, New York.

Staub, J.E., F.C. Serquen, T. Horejsi, and J.F. Chen. 1999. Genetic diversity in cucumber (Cucumis sativus L.): IV. An evaluation of Chinese germplasm. Genet. Resources Crop Evol. 46:297-310.

Staub, J.E., F.C. Serquen, and J.D. McCreight. 1997. Genetic diversity in cucumber (Cucumis sativus L): 3. An evaluation of Indian germplasm. Genet. Resources Crop Evol. 44:315-326.

Sun, Z., R.L. Lower, S.M. Chung, and J.E. Staub. 2006. Identification and comparative analysis of quantitative trait loci (QTL) associated with parthenocarpy in processing cucumber. Plant Breed. 125:281-287.

Tanksley, S.D., S. Grandillo, T.M. Fulton, D. Zamir, Y. Eshed, V. Petiard, J. Lopez, and T. Beck-Bunn. 1996. Advanced backcross QTL analysis in a cross between an elite processing line of tomato and its wild relative L. pimpinellifolium. Theor. Appl. Genet. 92:213-224. 
U.S. Department of Agriculture. 2010. National plant germplasm system: Germplasm resources information network. 7 Apr. 2010. $<$ http://www.ars-grin.gov/cgi-bin/npgs/swish/accboth?query= cucumis + sativus \& submit $=$ Submit + Text + Query $\& s i=0>$.

Wehrhahn, C. and R.W. Allard. 1965. The detection and measurement of the effects of individual genes involved in the inheritance of a quantitative character in wheat. Genetics 51:109-119.

Wright, S. 1978. Evolution and the genetics of populations. Variability within and among natural populations. University of Chicago Press, Chicago.
Yates, F. 1934. Contingency table involving small numbers and the $\chi 2$ test. J.R. Stat. Soc. 1:217-235.

Yuan, X., J.S. Pan, R. Cai, Y. Guan, L.Z. Liu, W.W. Zhang, Z. Li, H.L. He, C. Zhang, L.T. Si, and H. Zhu. 2008. Genetic mapping and QTL analysis of fruit and flower related traits in cucumber (Cucumis sativus L.) using recombinant inbred lines. Euphytica 164:473-491.

Zhou, X., C. Qian, Q. Lou, and J. Chen. 2009. Molecular analysis of introgression lines from Cucumis hystrix Chakr. to C. sativus L. Sci. Hort. 119:232-235. 